\title{
Esophageal Tumor
}

\author{
Xia Chen* \\ Department of Digestive Diseases, the Second Affiliated Hospital of Nanjing Medical University, China \\ *Corresponding author: Xia Chen, The Medical Center for Digestive Diseases, the Second Affiliated Hospital of Nanjing Medical University, Nanjing, \\ China
}

Submission: 悳 August 17, 2018 ; Published: 監 September 05, 2018

\begin{abstract}
Abbreviations: IARC: International Agency for Research on Cancer; ESCC: Esophageal Squamous Cell Carcinoma; SES: Socioeconomic Status; NBI: Narrow-Band Imaging; IPCL: Intrapapillary Capillary Loops; EUS: Endoscopic Ultrasound; CT: Computed Tomography; EMR: Endoscopic Mucosal Resection; ESD: Endoscopic Submucosal Dissection; EP: Epithelium; LPM: Lamina Propria Mucosae; EUS: Endoscopic Ultrasound; OS: Overall Survival; GERD: Gastroesophageal Reflux Disease; ESGE: European Society Of Gastrointestinal Endoscopy; EUS-FNA: Endoscopic Ultrasonography-Guided Fine Needle Aspiration; ESTD: Endoscopic Submucosal Tunnel Dissection
\end{abstract}

\section{Introduction}

Owing to the extremely aggressive nature and poor survival rate, esophageal cancer is referred as to one of the most difficult malignancies, with about 15\%-25\% for 5-year survival. According to global cancer statistics from International Agency for Research on Cancer (IARC), esophageal cancer is the 8th most common form cancer and the 6th most common death cause from cancer, accompanying with an estimation of 400,000 deaths in 2012 [1]. The incidence rate of esophageal cancer was considerably high in the northeastern part of West Asia, being the top ranking malignancy [2]. There are two main histological sub-types of esophageal cancer, esophageal squamous cell carcinoma (ESCC) and esophageal adenocarcinoma (EAC), which have almost completely distinct geographic patterns, time trends, and primary risk factors. There is high prevalence of ESCC in Asia, with up to 95\% cases in China. Otherwise, in Europe and United States the predominant histologic subtype is adenocarcinoma which arises on Barrett's esophagus. In this review, the epidemiology and risk factors of both, the strategy for detection in early stage, treatment and management will be reviewed briefly. Except that, other types tumor, including which arise from mesenchyme of esophagus will also be concerned.

\section{Esophageal Squamous Cell Carcinoma (ESCC) Epidemiology}

There were about 450,000 cases of esophageal cancer in 2012: 88\%were cases of ESCC and 12\% were cases of EAC based on the data from IARC. The geographic distribution of ESCC varies greatly, with the map that the area from Eastern to Central Asia has the highest incidence, following by Indian Ocean coast of Africa along the Great Rift Valley, and centralized around Uruguay in South America and encompassed the entire Gaucho Region of the continent has the third leading incidence. Particularly, China has about half of all ESCC cases all over the world partly because of its large large population of and the high incidence. Most Chinese patients gather in the North Central Taihung Mountain range, in where ESCC are the, or near the, leading cause of death, with incidence rates exceeding 125/100,000per year [3].

In many Western countries, the incidence of ESCC had been decreasing for several decades, whereas the incidence of adenocarcinoma has increased. Generally, ESCC is observed more frequently in men (69\%) than women (31\%), but it varies among low-risk area, like as United States with approaching 1:1 ratio. There is a difference among population subgroups, for example, African Americans are 7-fold more likely, to be diagnosed with ESCC than EAC, whereas US whites are about 4-fold more likely to develop EAC than ESCC [4].

\section{Known and suspected risk factors}

The etiology of ESCC is multi-factorial and strongly populationdependent. There are some known and suspected potential risk factors related to ESCC listed in (Table 1). Socioeconomic status (SES) is one of the most consistent risk factors for ESCC. In several studies, significant differences in risk factors are observed, which are strongly related with work, education, income, economical condition and compressed social status [5-7]. Tobacco smoking and chewing are large risk factors for ESCC in developed countries with an approximate 3- to 9-fold relative risk in current smokers, while relative risk of approximately 1.5 fold in developing countries $[8,9]$. Smoking tobacco is suggested to be relevant risk of ESCC in both exposure intensity and duration. It has been confirmed that alcohol consumption is a risk factor for ESCC in economically developing as well-developed areas, increasing 1.6-9fold risk in varied area of the world [10]. Notably, combination of tobacco and 
alcohol may increase the risk of ESCC compared with the predicted multiplicative risk of either one alone. Large scale cohort studies are needed to support the findings even though many studies have reported the interactions [11].

Table 1: Risk factors for esophageal squamous cell cancer.

\begin{tabular}{|c|c|}
\hline Consistent Evidence & $\begin{array}{c}\text { Reported but } \\
\text { not Confirmed }\end{array}$ \\
\hline Poverty & PAHs \\
\hline Tobacco & Poor oral health \\
\hline Alcohol & $\begin{array}{c}\text { Reproductive } \\
\text { factors }\end{array}$ \\
\hline Eating behavior (e.g.hot food, Pickled vegetables ) & \multirow{2}{*}{ Gastric atrophy } \\
\hline Radiation & \multirow{2}{*}{ Opium } \\
\hline Achalasia & \\
\hline Fnaconi anemia &
\end{tabular}

Although there is disagree with that higher intake of fruits and vegetables probably decreases the risk of esophageal cancer, it is reported that each increment of $50 \mathrm{~g} / \mathrm{d}$ of raw vegetables was associated with $31 \%$ decrease in risk of esophageal cancer, while the same increment intake of fruit was associated with a $22 \%$ decrease [12]. The mutagenicity and carcinogenicity of pickled vegetables have been shown in some animal and in vitro studies. In China, pickled vegetables were an mainly comprise of the diet in many families for even 9-12 months a year. A meta-analysis showed that the intake of pickled vegetables increase a 2-fold higher risk of ESCC [13]. Consumption of hot food and beverages has been associated with increased risk of ESCC in multiple studies. Lowering the temperature of consumption is also important in preventive education for residents in high risk area. Proposed mechanisms for the association between poor oral health and ESCC include the potential for inflammation associated with periodontal disease to have distant effects. Some researchers suggested the relationship between the poor oral health and ESCC should be investigated.

\section{Early detection}

The detection at an early stage of esophageal is critical in improving outcomes of mortality significantly. Squamous dysplasia is the precursor lesion of ESCC. With the development of endoscopic technique, it turns out that early screening is feasible and plays more and more important role in management of esophageal cancer. The detection and characterization of superficial neoplasia as subtle and flat can be challenging with high-definition white-light endoscopy. In practice, endoscopist characterize suspicious lesions by means of Lugol staining and Narrow-band imaging (NBI). Cicatricial or parakeratotic lesions that may appear as Lugol-negative can be shown in pattern of the intrapapillary capillary loops (IPCL) by NBI, which in turn can be used to predict the degree of malignancy and invasiveness of the lesion [14]. Several studies have concurred on the fact that irregular vascular and mucosal features based on IPCL criterion are associated to early neoplasia [15-17], with 96\% sensitivity and $94 \%$ specificity for the diagnosis of HGD. Endoscopic ultrasound (EUS) is not routinely recommended in the workup of all early esophageal cancers, however, EUS is able to detect regional lymph nodes with a sensitivity of $76 \%$ and a specificity of $72 \%$, significantly better than computed tomography (CT) scan [18]. EUS-guided fine-needle aspiration can then increase the diagnostic accuracy of the N-staging to $90 \%$ in advanced carcinomas [19]. In China, endoscopic screening in high-risk areas, such as Linxian, has been shown to detect precursor lesions in asymptomatic patients with high-grade dysplasia, which is associated with an RR of 28.3 (95\%CI: 15.3-52.3) for developing the disease compared to patients who have a normal esophageal mucosa [20].

\section{Treatment}

Choosing proper treatment for ESCC depends on its stage, classified based on TNM system (Table 2). For early stage mucosal cancer, endoscopic mucosal resection (EMR) and endoscopic submucosal dissection (ESD) are considered, while for locally advanced cancer, esophagectomy remains the mainstream. Chemotherapy and chemoradiotherapy is traditional options while ESCC go far advanced stage. Apart from that, immunotherapy has recently gained increased attention as a new era for cancer treatment.

Table 2: The seventh edition of TNM staging system for esophageal cancer published by The American Joint Committee on Cancer (AJCC) and the Union for International Cancer Control (UICC).

\begin{tabular}{|c|c|}
\hline \multicolumn{2}{|r|}{ TNM Staging System for Esophageal Cancer } \\
\hline \multirow{7}{*}{ Tumor } & Tis: high-grade dysplasia \\
\hline & $\begin{array}{l}\text { T1: invasion of lamina propria, musculars mucosae, or } \\
\text { submucosa }\end{array}$ \\
\hline & T2: invasion of muscularis propria \\
\hline & T3: invasion of adventitia \\
\hline & T4: invasion of adjacent structures \\
\hline & T4a: resectable (pleura, pericardium, or diaphragm) \\
\hline & T4b: unresectable (aorta, vertebral body, or trachea) \\
\hline \multirow{4}{*}{ Node } & N0: absent \\
\hline & N1: $1-2$ regional LNs \\
\hline & N2: 3-6 regional LNs \\
\hline & N3: $\geq 7$ regional LNs \\
\hline \multirow{2}{*}{ Metastasis } & M0: absent \\
\hline & M1: present \\
\hline
\end{tabular}

Notes: LN: lymph node

Endoscopic treatment: EMR and ESD are applied for lesions which are limited to the mucosal layer, or those confined to the epithelium (EP) or the lamina propria mucosae (LPM), as it is very unusual for there to be lymph node metastasis in these circumstances. The accurate evaluation of depth of invasion at early stage(T1) measured by Endoscopic ultrasound (EUS) with the accuracy of $60.3 \%-74.3 \%$ [21]. A recent meta-analysis showed that ESD was significantly more effective than EMR for en bloc resection, 
complete resection, curative resection, and local recurrence, but with more complications, such as intraoperative bleeding, perforation risk. And operation time was significantly greater for ESD. However, overall bleeding risk and all-cause mortality did not differ significantly between ESD and EMR [22]. In general, EMR is

Table 3: Characteristics of EMR and ESD. indicated for smaller tumors, and ESD for more extensive lesions (Table 3). Nevertheless, with acknowledge of the advantages of ESD and controlling complications being less and less by more strategies, it is recently also being used for smaller lesions.

\begin{tabular}{|c|c|}
\hline EMR & ESD \\
\hline Time for resection is short & Time for dissection is longer than EMR \\
\hline The range of en bloc resection is small $(\leq 20 \mathrm{~mm})$ & $\begin{array}{c}\text { The range of en bloc dissection is large (no obvious } \\
\text { restriction) }\end{array}$ \\
\hline Pathological evaluation is difficult when the tumor is resected piecemeal & Accurate pathological evaluation is possible \\
\hline $\begin{array}{c}\text { Complication related to the procedure is rare (e.g., perforation, mediastinal emphysema, and } \\
\text { structure) }\end{array}$ & Complication is possibly frequent \\
\hline
\end{tabular}

Surgical treatment: The patients in stages beyond T1 without evidence of invasion to the adjacent organs or distant metastasis are recommended by esophagectomy followed by reconstructive surgery. The three most common techniques for thoracic esophagectomy are the transhiatal approach, the Ivor Lewis esophagectomy (right thoracotomy and laparotomy), and the McKeown technique (right thoracotomy followed by laparotomy and neck incision with cervical anastomosis). No important differences between esophagectomy with transthoracic esophagectomy was detected in a large randomized trial study [23], but, a better survival rate was found in en bloc esophagectomy compared with transhiatal esophagectomy [24], which indicating the superiority of extended en bloc esophagectomy over transhiatal resection when the tumor is in the lower esophagus or cardia.

Transhiatal esophagectomy was linked with lower morbidity than transthoracic esophagectomy with extended en bloc lymphadenectomy. Although disease-free and quality-adjusted survival showed no statistically differences, there was a trend toward improved long-term survival at 5 years with the extended transthoracic approach. In Japan, the extended transthoracic esophagectomy with three-field (cervical, mediastinal, abdominal) was reported superior to two-field dissection [25]. For, cervical esophageal cancer, extensive en bloc resection that includes the hypopharynx, esophagus, larynx, thyroid, parathyroid, cervical lymph nodes, and a permanent tracheostomy are needed in many cases. Future quality of life is a major issue for these patients, owing to the extent of radical surgery, which often includes laryngectomy. Definitive chemoradiotherapy has the potential to down-stage and even cure the disease without altering quality of life dramatically. However, randomized trials are required for supporting the opinion.

Chemotherapy and chemoradiotherapy: Chemotherapy are potential tumour downstaging prior to surgery, as well as targeting micro-metastases and, thus, decreasing the risk of distant metastasis. But, there is a study reported no survival benefit, with a median survival of 14.9 months in patients treated with chemotherapy compared with 16.1 months in those receiving surgery alone $(\mathrm{P}=0.53)$ [26]. Five-year overall survival (OS) was $17.1 \%$ in the group that underwent surgery alone compared with $23.0 \%$ in the neoadjuvant chemotherapy group $(\mathrm{P}=0.03)$ [27]. Compared ad- juvant chemotherapy and surgery alone (JCOG 9204) [28], a study from Japan found that the addition of adjuvant chemotherapy improved the disease-free survival rate (from 45 to $55 \%$; $\mathrm{P}=0.037$ ) and the pN1 subgroup 5-year OS (52 versus 38\%, $\mathrm{P}=0.041$ ) [28]; however, there was no significant difference in the 5 -year OS of the whole cohort (61\% with chemotherapy versus $52 \%$ with observation; $\mathrm{P}=0.13$ ). Chemoradiotherapy is the standard therapy for unresectable esophageal cancer and should be considered as an option for resectable esophageal cancer. Median survival was 12.5 months in the chemoradiotherapy group and 8.9 months in the group exposed to radiotherapy alone $(\mathrm{p}=0.001)$ [29]. A trail including randomized 236 patients with unresectable T14, N0/1, M0 exposed to a standard dose (50.4Gy) or high radiation dose (64.8Gy) with concurrent chemotherapy showed there was no benefit, even, a trend towards reduced survival-for those patients in the high dose arm (2-year overall survival of 31 versus 40\%) [30].

Immunotherapy: With increasing clinical experience, biomarker analyses, and improvements in preclinical models, the possibility of immunotherapy for esophageal cancers is arising. The anticancer effects have been supported by the development of inhibitory antibodies, such as cytotoxic T-lymphocyte antigen 4 (CTLA-4), programmed cell death protein 1(PD-1), and programmed death ligand 1 (PD-L1). Applying immunohistochemical and RTPCR approaches, it was found that there was 43.9\% (41 ESCC) of samples had either PD-L1 or PD-L2 overexpressing tumor cells [31]. Although there is no more data supporting the efficiency of immunotherapy in ESCC, PD-L1 expression level is comparable to cancers in which anti- PD-L1 directed therapies has the potential of early success. Surely, more clinical trails about immonotherapy are needed to undergoing.

\section{Esophageal Adenocarcinoma (EAC)}

Most patients with EAC which mainly arise from Barrett's, esophagus, a special condition of gastroesophageal reflux disease (GERD), were from Europe, Northern America, or Oceania.

\section{Epidemiology}

Estimated 52,000 individuals developed EAC worldwide in 2012 , with a incidence rate of $0.7 / 100,000$ person/years; It has already surpassed others esophageal cancer in some Western 
countries [32] Apart from the geographic variation, EAC presented age-standardized incidence with the highest one in Northern and Western Europe, Northern America, and Oceania. For sexspecific incidence, there is 7.2 in men to 2.5 in women rate per 100,000 person-years in the UK, 7.1 in men to 2.8 in women in the Netherlands, and 3.9 in men and 2.7 in women Ireland [32]. In US, Non-Hispanic white has highest incidence rate of EAC, followed by Hispanic whites, American Indian/Alaska, Native, blacks, and lowest in Asian/Pacific islanders [33].

\section{Risk factors}

An analysis of 5 pooled population-based case-control studies showed the risk of EAC in individuals with heartburn for at least 30 years was 6.2-fold higher than in individuals without heartburn, indicating a strong association between GERD and EAC risk [34], and, the association was stronger in adults younger than 50 years compared with older age groups. Besides, Barrett's esophagus, which arises from GERD, is the precursor to EAC. It is characterized by metaplastic changes in the gastroesophageal junction in patients with long term GERD symptom, from normal squamous to a specialized columnar epithelium. The development process involves consecutive changes, from erosive esophagitis to nondysplastic BE, low-grade dysplasia, high-grade dysplasia then EAC.

Obesity has been consistently associated with increasing risk of EAC. The possible mechanism might be GERD because of extensive intra-abdominal adipose tissue causing increased intra-gastric pressure and disruption of the gastroesophageal junction and the lower esophageal sphincter. Moreover, Obesity is a systemic disease that may increase EAC risk through inflammatory and metabolic alterations. Studies have indicated associations between serum leptin and insulin levels, as well as metabolic syndrome components, and an altered risk of BE. A large prospective cohort study (580, 000 participants) showed the relationship between an increased risk of EAC and the metabolic syndrome [35].

\section{International barrett's and esophageal adenocarcinoma}

Consortium (BEACON) has reported a dose-response association between pack-years of tobacco smoking and EAC risk, with a 2.7-fold increased risk for individuals who had 45 or more pack-years of smoking history [36]. However, the risk of EAC in former smokers does not recover the level that of never-smokers. Then the priority prevention of smoking uptake in the population, particularly among young people, should remain strongly recommendation. A 20\% increase in risk of EAC was reported in individuals with alcohol-use disorders in a registry cohort study [37], even though it has not been confirmed that proper amount alcohol consumption increases the risk of EAC. Vegetable intake most likely reduced the risk of EAC. Intake of vitamin C, magnesium, folate, vitamin B6, and non-heme iron were considered helpful reducing risks of esophagitis, $\mathrm{BE}$, and EAC [38].

A whole-exome sequencing study of a multi-generational family, in which 14 members were with BE or EAC, found a variant in the V-set and immunoglobulin domain containing 10 like gene (VSIG10L), encoding S631G, as a potential underlying reason of familial EAC [39]. The finding provides opportunities for screening and surveillance of individuals with family members affected by BE or EAC, depending on its prevalence. Studies with a large number of patients showed that the use of non-steroidal anti-inflammatory drugs (NSAIDs), proton pump inhibitors (PPIs) and statins in patients with BE, reduced the progression to adenocarcinoma [40].

\section{Strategy for management of EAC}

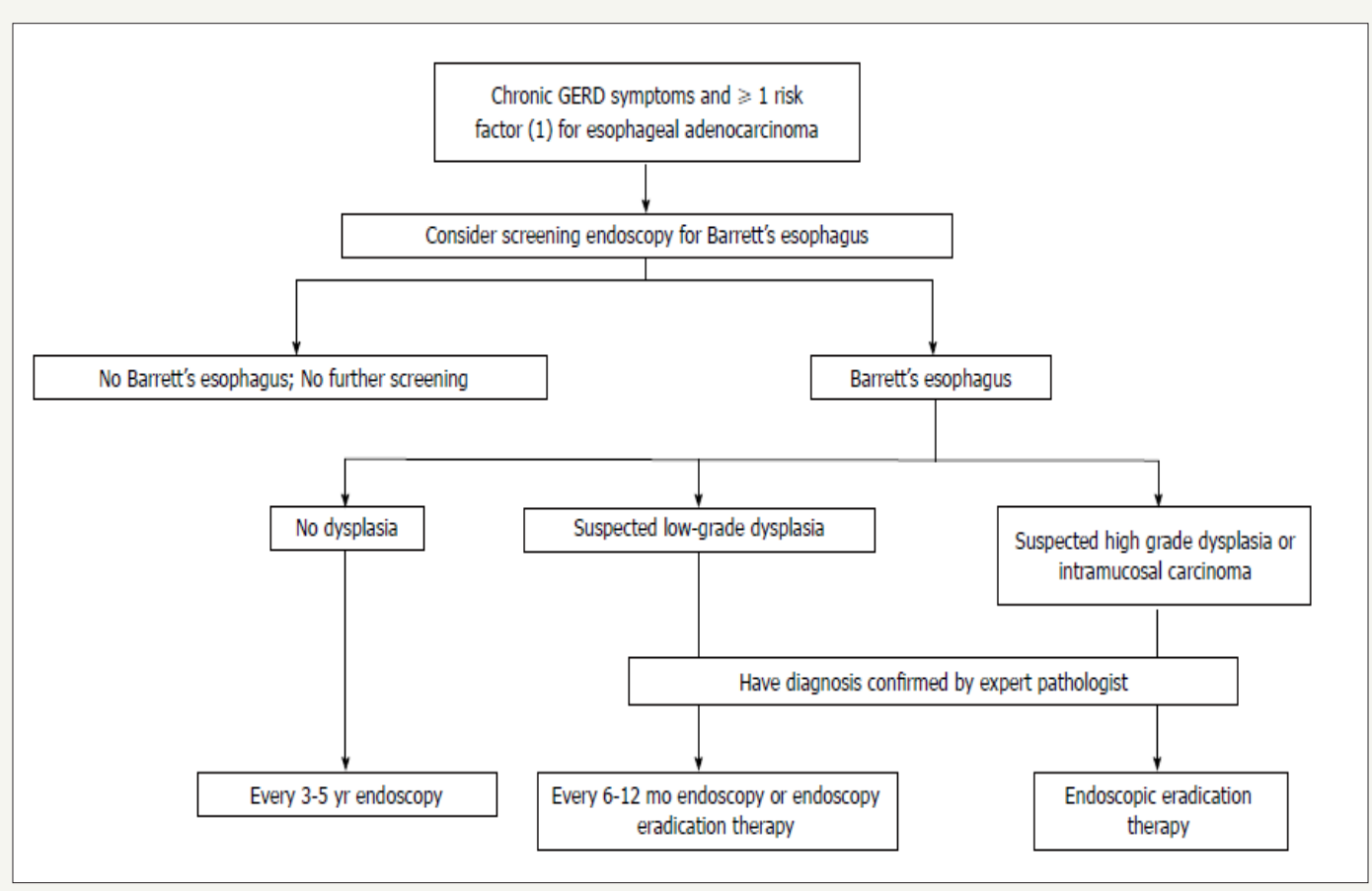

Figure 1: Algorithm for the screening surveillance, and management of Barrett's esophagus. From reference [42]. 
Screening and surveillance: According to current guidelines, endoscopy screening of EAC is strongly recommended accompanying with taking biopsies in all 4 quadrants and each $2 \mathrm{~cm}$ of columnar epithelium, and ideally performed with highresolution endoscopes and NBI. The annual risk is about $1 \%$ for patients with low-grade dysplasia and more than $5 \%$ for patients with high-grade dysplasia. Endoscopic screening found out $6 \%$ to $12 \%$ of patients with prolonged GERD symptoms bearing with $\mathrm{BE}$, most frequently white men older than 50 years of age $[41,42]$. Some experts suggest that the patient with chronic GERD symptoms and at least 1 risk factor for esophageal carcinoma are supposed to do endoscopic screening. Early adenocarcinoma with adequate surveillance depends on the evidences of endoscopy and pathology (Figure 1). Economic modelling analyses of surveillance of $\mathrm{BE}$ showed that the screening of 50 -or 55 years old white men with GERD symptom was very sensitive to the incidence of adenocarcinoma and the incremental cost-effectiveness ratio for 5 -yearly surveillance was no longer within the range usually considered cost-effective [43]. However, Studies have shown that patients with EAC detected during endoscopic surveillance for BE are more likely to have early-stage cancer, receive curative therapy, and survive longer than symptomatic patients with EAC during the clinical workout [41].

Endoscopic treatment: The first and better choice in the treatment of early adenocarcinoma and Barrett's neoplasia is EMR. There are two types of EMR. One is standard EMR technique with a large straight or oblique cap of $12 \mathrm{~mm}$ inner diameter with a distal ridge, allowing for the placement of an asymmetrical snare after submucosal lifting. Another is the multiband EMR technique, which uses a modified variceal band ligator and a 5-7F polypectomy snare. A randomized controlled study comparing both techniques showed that multiband EMR was cheaper and quicker than capEMR, but similarly safe, despite the absence of submucosal lifting [44]. Noticeably, unlike to squamous neoplasia, the latest guidelines released by European Society of Gastrointestinal Endoscopy (ESGE) recommended that piecemeal EMR should be preferred over ESD in most cases [45] although the development of ESD in western centers that specialize in Barrett's esophagus may change therapeutic paradigms in the near future.

Radiofrequency ablation (RFA) is a method for complete eradication of the remaining Barrett's mucosa. Currently, EMR of visible lesions and RFA of the remaining Barrett's esophagus is the gold standard in the endoscopic treatment of Barrett's neoplasia. The efficacy of this approach has been tested with $90 \%$ complete eradication of intestinal metaplasia and neoplasia at 5years [46]. Especially, for long circumferential Barrett's esophagus, this strategy surpassed other other ablative techniques in time-saving and efficiency.

Surveillance after resection Based on current guidelines, close endoscopic surveillance and prolonged follow up is still recommended even though the risk of local or metachronous recurrence of EAC is largely reduced by the systematic ablation of the residual Barrett's esophagus. The risk of lymph-node metastases associated with EAC can be estimated by the depth of tumor infiltration and the differentiation grade and the presence of lymphovascular involvement. Additional therapy by esophagectomy with lymph-node dissection should be considered with deeper infiltration in the submucosa, positive vertical margins, or the presence of poor qualitative histoprognostic features.

Surgery Esophagectomy, which has long been the gold standard for the treatment of localized esophageal cancer, including early esophageal cancer, results in $2-5 \%$ mortality and $30-40 \%$ severe morbidity, and lowering the patients' quality of life [47]. Well designed prospective studies about comparing of the outcomes of surgical and endoscopic treatment are needed for completely evaluated them in all aspects. Nevertheless, although with higher local recurrence rates and metachronous lesions in the endoscopic treatment, it still seems preferable to surgery as a first-line treatment approach for early esophageal neoplasia because all problems could be managed endoscopically with no impact on survival.

\section{Strategy for Esophageal Non-epithelial Tumors}

Esophageal non-epithelial tumors are uncommon with a less than $1 \%$ of esophageal tumors, which comprised over $90 \%$ benign tumors, but it still exists the possibility of malignancies,such as GIST and leiomyosarcoma. There is no consensus has been reached as to the best diagnostic methods and treatments for esophageal nonepithelial tumors in case of the limited data from clinical practice. Generally, as a endoscopist found suspected lesions that come from non- epithelium of esophagus, computed tomography (CT) scanning is their first choice to differentiate from cysts and lipomas/ liposarcomas. Following endoscopic ultrasonography-guided fine needle aspiration (EUS-FNA), it can provide pathological diagnosis.

For tumors that are too small to aspiration, an incisional biopsy through ESD or EMR should be considered because ESD/EMR will be a better method for dealing with tumors that are located on the superficial layer. It is reported that EUS-FNA is a sensitive method for tissue sampling of suspicious lesions of the gastrointestinal lumen and adjacent structures, including esophageal lesions, gastric malignancies and pancreaticobiliary, mediastinal and intraabdominal lymphadenopathies [48]. The technique of endoscopic biopsy can achieve a diagnostic accuracy of $60-90 \%$, it should be noticed that the accuracy depends on the site being evaluated. The suggested procedure is summarized [49].

Endoscopic and surgical treatment can be chosen according the location of the lesion. Totally, endoscopic treatment should be a prior option for these tumors which are located on the superficial layer. A study showed endoscopic submucosal tunnel dissection (ESTD), which is a technique similar to SET, is safe and effective for the resection of esophageal leiomyoma with shorter operating and heaing times, reducing hospital stay, no compromise in the success rate or an increase in complications [50]. There is not a standard of diameter for the lesion suitable to endoscopic treatment. Some endoscopists found radical resection for esophageal non-epithelial tumors with big diameter from $20 \mathrm{~mm}$ to $40 \mathrm{~mm}$ could be performed by ESD without complications [51]. However, the efficiency and safety of performing ESD/EMR is heavily biased on the experience 
of the performer and there are so many differences between varied endoscopists even for the same procedure and the same lesion location. Then more researches focus on endoscopic therapy are truly needed in the future to give rise to a conclusion.

It is important to distinguish GIST from other esophageal non-epithelial tumors, because the surgical procedure for GIST is different. Surgical treatment for benign esophageal non-epithelial tumors includes enucleation or partial resection, and observation would be one option if the patient does not present any symptoms. But dealing with a GIST, curative resection with free surgical margins is necessary, Meanwhile, the surgical procedure varies to tumor location and whether chemotherapy is followed.

\section{References}

1. Ferlay J, Soerjomataram I, Dikshit R, Eser S, Mathers C, et al. (2015) Cancer incidence and mortality worldwide: sources, methods and major patterns in GLOBOCAN 2012. Int J Cancer 136: E359-E386.

2. Roshandel G, Boreiri M, Sadjadi A, Malekzadeh R (2014) A diversity of cancer incidence and mortality in West Asian populations. Ann Glob Health 80(5): 346-3457.

3. Blot WJ, Li JY (1985) Some considerations in the design of a nutrition intervention trial in Linxian, People's Republic of China. Natl Cancer Inst Monogr 69: 29-34.

4. Cook MB, Chow WH, Devesa SS (2009) Oesophageal cancer incidence in the United States by race, sex, and histologic type, 1977-2005. Br J Cancer 101(5): 855-859.

5. Jansson C, Johansson AL, Nyren O, Lagergren J (2005) Socioeconomic factors and risk of esophageal adenocarcinoma: a nationwide Swedish case-control study. Cancer Epidemiol Biomarkers Prev 14(7): 17541761.

6. Gammon MD, Schoenberg JB, Ahsan H, Risch HA, Vaughan TL, et al. (1997) Tobacco, alcohol, and socioeconomic status and adenocarcinomas of the esophagus and gastric cardia. J Natl Cancer Inst 89(17): 1277-1284

7. Wei WQ, Abnet CC, Lu N, Roth MJ, Wang GQ et al. (2005) Risk factors for oesophageal squamous dysplasia in adult inhabitants of a high risk region of China. Gut 54(6): 759-763.

8. Ishiguro S, Sasazuki S, Inoue M, Kurahashi N, Iwasaki M, et al. (2009) Effect of alcohol consumption, cigarette smoking and flushing response on esophageal cancer risk: a population-based cohort study (JPHC study). Cancer Lett 275(2): 240-246.

9. Okello S, Churchill C, Owori R, Nasasira B, Tumuhimbise C, et al. (2016) Population attributable fraction of esophageal squamous cell carcinoma due to smoking and alcohol in Uganda. BMC Cancer 16: 446.

10. Kim MK, Ko MJ, Han JT (2010) Alcohol consumption and mortality from all-cause and cancers among 1.34 million Koreans: the results from the Korea national health insurance corporation's health examinee cohort in 2000. Cancer Causes Control 21(12): 2295-2302.

11. Prabhu A, Obi KO, Rubenstein JH (2014) The synergistic effects of alcohol and tobacco consumption on the risk of esophageal squamous cell carcinoma: a meta-analysis. Am J Gastroenterol 109(6): 822-827.

12. Engel LS, Chow WH, Vaughan TL, Gammon MD, Risch HA, et al. (2003) Population attributable risks of esophageal and gastric cancers. J Natl Cancer Inst 95(18): 1404-1413.

13. Islami F, Ren JS, Taylor PR, Kamangar F (2009) Pickled vegetables and the risk of oesophageal cancer: a meta-analysis. Br J Cancer 101(9): 1641-1647.

14. Inoue $H$, Kaga M, Ikeda H, Sato C, Sato H, et al. (2015) Magnification endoscopy in esophageal squamous cell carcinoma: a review of the intrapapillary capillary loop classification. Ann Gastroenterol 28(1): 4148.

15. Curvers W, Baak L, Kiesslich R, Van Oijen A, Rabenstein T, et al (2008) Chromoendoscopy and narrow-band imaging compared with high-resolution magnification endoscopy in Barrett's esophagus. Gastroenterology 134(3): 670-679.

16. Mannath J, Subramanian V, Hawkey CJ, Ragunath K (2010) Narrow band imaging for characterization of high grade dysplasia and specialized intestinal metaplasia in Barrett's esophagus: a meta-analysis. Endoscopy 42(5): 351-359

17. Sharma P, Bergman JJ, Goda K, Kato M, Messmann H, et al. (2016) Development and validation of a classification system to identify highgrade dysplasia and esophageal adenocarcinoma in Barrett's esophagus using narrow-band imaging. Gastroenterology 150(3): 591-598.

18. Pech O, May A, Günter E, Gossner L, Ell C (2006) The impact of endoscopic ultrasound and computed tomography on the TNM staging of early cancer in Barrett's esophagus. Am J Gastroenterol 101(10): 2223-2229.

19. Klapman J, Chang KJ, Wiersema M, Murata Y, Vilmann P (2005) Endoscopic ultrasound-guided fine-needle aspiration biopsy in esophageal cancer. Endoscopy 37: 381-385.

20. Wang GQ, Abnet CC, Shen Q Lewin KJ, Sun XD, et al. (2005) Histological precursors of oesophageal squamous cell carcinoma: results from a 13year prospective follow up study in a high risk population. Gut 54(2): 187-192.

21. Jeong DY, Kim MY, Lee KS, Choi JY, Kim SJ, et al. (2018) Surgically resected T1- and T2-stage esophageal squamous cell carcinoma: T and N staging performance of EUS and PET/CT. Cancer Med 7(8): 3561-3570.

22. Park YM, Cho E, Kang HY, Kim JM (2011) The effectiveness and safety of endoscopic submucosal dissection compared with endoscopic mucosal resection for early gastric cancer: a systematic review and metaanalysis. Surg Endosc 25(8): 2666-2677.

23. Rentz J, Bull D, Harpole D, Bailey S, Neumayer L (2003) Transthoracic versus transhiatal esophagectomy: a prospective study of 945 patients. J Thorac Cardiovasc Surg 125(5): 1114-1120.

24. Hagen JA, Peters JH, De Meester TR (1993) Superiority of extended en bloc esophagogastrectomy for carcinoma of the lower esophagus and cardia. J Thorac Cardiovasc Surg 106(5): 850-858.

25. Isono K, Sato H, Nakayama K (1991) Results of a nationwide study on the three-field lymph node dissection of esophageal cancer. Oncology 48(5): 411-420.

26. Kelsen DP, Winter KA, Gunderson LL, Mortimer J, Estes NC, et al. (2007) Long-term results of RTOG trial 8911 (USA Intergroup 113): a random assignment trial comparison of chemotherapy followed by surgery compared with surgery alone for esophageal cancer. J Clin Oncol 25(24): 3719-3725.

27. Allum WH, Stenning SP, Bancewicz J, Clark PI, Langley RE (2009) Long-term results of a randomized trial of surgery with or without preoperative chemotherapy in esophageal cancer. J Clin Oncol 27(24): 5062-5067.

28. Ando N, Iizuka T, Ide H, Ishida K, Shinoda M, et al. (2003) Surgery plus chemotherapy compared with surgery alone for localized squamous cell carcinoma of the thoracic esophagus: a Japan Clinical Oncology Group Study-JCOG9204. J Clin Oncol 21(24): 4592-4596.

29. Cooper JS, Guo MD, Herskovic A, Macdonald JS, Martenson JA, et al (1999) Chemoradiotherapy of locally advanced esophageal cancer: long-term follow-up of a prospective randomized trial (RTOG 85-01). Radiation Therapy Oncology Group. JAMA 281(17): 1623-1627.

30. Minsky BD, Pajak TF, Ginsberg RJ, Pisansky TM, Martenson J, et al. (2002) INT 0123 (Radiation Therapy Oncology Group 94-05) phase III trial of combined-modality therapy for esophageal cancer: high-dose versus standard-dose radiation therapy. J Clin Oncol 20(5): 1167-1174. 
31. Ohigashi Y, Sho M, Yamada Y, Tsurui Y, Hamada K, et al. (2005) Clinical significance of programmed death-1 ligand-1 and programmed death-1 ligand-2 expression in human esophageal cancer. Clin Cancer Res 11(8): 2947-2953.

32. Arnold M, Soerjomataram I, Ferlay J, Forman D (2015) Global incidence of oesophageal cancer by histological subtype in 2012. Gut 64(3): 381387.

33. González L, Magno P, Ortiz AP, Ortiz Ortiz K, Hess K, et al. (2013) Esophageal cancer incidence rates by histological type and overall: Puerto Rico versus the United States Surveillance, Epidemiology, and End Results population, 1992-2005. Cancer Epidemiol 37(1): 5-10.

34. Cook MB, Corley DA, Murray LJ, Liao LM, Kamangar F, et al. (2014) Gastroesophageal reflux in relation to adenocarcinomas of the esophagus: a pooled analysis from the Barrett's and Esophageal Adenocarcinoma Consortium (BEACON). PLoS One 9(7): e103508.

35. Lindkvist B, Johansen D, Stocks T, Concin H, Bjørge T, et al. (2014) Metabolic risk factors for esophageal squamous cell carcinoma and adenocarcinoma: a prospective study of 580,000 subjects within the MeCan project. BMC Cancer 14: 103.

36. Cook MB, Kamangar F, Whiteman DC, Freedman ND, Gammon MD, et al. (2010) Cigarette smoking and adenocarcinomas of the esophagus and esophagogastric junction: a pooled analysis from the international BEACON consortium. J Natl Cancer Inst 102(17): 1344-1353.

37. Ji J, Sundquist J, Sundquist K (2017) Associations of alcohol use disorders with esophageal and gastric cancers: a population-based study in Sweden. Eur J Cancer Prev 26(2): 119-124

38. O’Doherty MG, Abnet CC, Murray LJ, Woodside JV, Anderson LA, et al. (2010) Iron intake and markers of iron status and risk of Barrett's esophagus and esophageal adenocarcinoma. Cancer Causes Control 21(12): 2269-2279.

39. Chak A, Ochs Balcom H, Falk G, Grady WM, Kinnard M, et al. (2006) Familiality in Barrett's esophagus, adenocarcinoma of the esophagus, and adenocarcinoma of the gastroesophageal junction. Cancer Epidemiol Biomarkers Prev 15(9): 1668-1673.

40. Wheeler JB, Reed CE (2012) Epidemiology of esophageal cancer. Surg Clin North Am 92(5): 1077-1087.
41. Rustgi AK, El Serag HB (2014) Esophageal carcinoma. N Engl J Med 371(26): 2499-2509.

42. Domper Arnal MJ, Ferrández Arenas Á, Lanas Arbeloa Á (2015) Esophageal cancer: Risk factors, screening and endoscopic treatment in Western and Eastern countries. World J Gastroenterol 21(26): 7933 7943.

43. Garside R, Pitt M, Somerville M, Stein K, Price A, et al. (2006) Surveillance of Barrett's oesophagus: exploring the uncertainty through systematic review, expert workshop and economic modelling. Health Technol Assess 10(8): 1-142.

44. Pouw RE, Van Vilsteren FG, Peters FP, Alvarez Herrero L, Ten Kate FJ (2011) Randomized trial on endoscopic resection-cap versus multiband mucosectomy for piecemeal endoscopic resection of early Barrett's neoplasia. Gastrointest Endosc 74(1): 35-43.

45. Pimentel Nunes P, Dinis Ribeiro M, Ponchon T, Repici A, Vieth M, et al. (2015) Endoscopic submucosal dissection: European Society of Gastrointestinal Endoscopy (ESGE) Guideline. Endoscopy 47(9): 829854.

46. Phoa KN, Pouw RE, Bisschops R, Pech O, Ragunath K, et al. (2016) Multimodality endoscopic eradication for neoplastic Barrett oesophagus: results of an European multicentre study (EURO-II). Gut 65(4): 555-562.

47. Pennathur A, Gibson MK, Jobe BA, Luketich JD (2013) Oesophageal carcinoma. Lancet 381(9864): 400-412.

48. Wang R, Wang J, Li Y, Duan Y, Wu X, et al. (2017) Diagnostic accuracies of endoscopic ultrasound-guided fine-needle aspiration with distinct negative pressure suction techniques in solid lesions: a retrospective study. Oncol Lett 13(5): 3709-3716.

49. Aoki T, Nakamura T, Oshikiri T, Hasegawa H, Yamamoto M, et al. (2018) Strategy for esophageal non-epithelial tumors based on a retrospective analysis of a single facility. Esophagus 13(5): 3709-3716.

50. Wang L, Ren W, Zhang Z, Yu J, Li Y, et al. (2013) Retrospective study of endoscopic submucosal tunnel dissection (ESTD) for surgical resection of esophageal leiomyoma. Surg Endosc 27(11): 4259-4266.

51. Wehrmann T, Marchenko K, Nakamura M, Riphaus A, Stergiou N (2004) Endoscopic resection of submucosal esophageal tumors: a prospective case series. Endoscopy 36(9): 802-807.

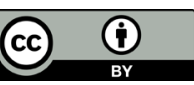

Creative Commons Attribution 4.0 International License

For possible submissions Click Here

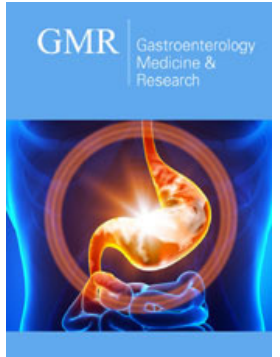

\section{Gastroenterology Medicine \& Research}

\section{Benefits of Publishing with us}

- High-level peer review and editorial services

- Freely accessible online immediately upon publication

- Authors retain the copyright to their work

- Licensing it under a Creative Commons license

- Visibility through different online platforms 